Научная статья

УДК 379.8.093

DOI: $10.17213 / 2075-2067-2021-6-228-236$

\title{
ПРАКТИКИ ЭТНОКУЛЬТУРНОГО ТУРИЗМА: ЭКЗИСТЕНЦИОНАЛЬНЫЕ АСПЕКТЫ
}

\author{
Елена Валерьевна Дашкова
}

\section{Чеченский государственный университет им. А. А. Кадырова, Грозный, Россия dashkova@mail.ru, ORCID: 12689863,AuthorID РИНЦ: 619408}

Аннотация. Целью исследования является определение экзистенциональных аспектов этнографического туризма, возможности использования «захваченности» человека интересом к этническим культурам в рамках этнокультурного туризма и развитием способности к реконструкции собственной этнической культуры.

Методологическую базу исследования представляют базисные понятия экзистенциализма в сфере межкультурного взаимодействия. Теоретическую и методологическую основу исследования составили исследования зарубежнных и отечественных философов и культурологов. В статье используется диалектический метод, позволяющий выявить наиболее общие закономерности развития представлений об этнокультурном туризме. К используемым научным методам относятся метод причинно-следственных связей, метод сравнения, метод моделирования.

Результаты исследования. Рассматриваемый феномен этнокультурного туризма характеризуется высоким уровнем межкультурных взаимодействий, происходящии в проиессе знакомства с этническими культурами. Межкультурное взаимодействие выступает важной частью социальных интеракций, происходящих, как правило, между носителями различных культурных паттернов. Межкультурное взаимодействие может иметь дифференцированные формы, связанные с глобальными культурными различиями. Но вместе с тем развитие межкультурных интеракций между народами, позволяющеее преодолевать кризисы коммуникации, способствует распространению человеческой свободы, во многом основанной на ответственности одних сообществ перед другими. Этнокультурный туризм является инструментом, позволяющим усилить контакты между народами, направленные во многом на кросс-культурное сотрудничество, преодоление ксенофобии и других форм нетерпимости. Исходя из персоналистической установки в современной философии, а также того внимания, которое философы уделяют коммуникации и собственно языку, можно сделать вывод, что личностью является человек, способный вести межкультурный диалог, не боясь и не стесняясь, но вместе с тем уважая представителей других культур, партнеров и друзей по межкультурным интеракциям. Появление этнокультурного туризма свидетельствует о прогрессе в сфере человеческой свободы. Проведенный анализ позволяет рассматривать этнокультурный туризм в качестве самостоятельной духовной иенности, важной для развития глобальной культуры.

Перспективы исследования заключаются в дальнейшем исследовании практик этнокультурного туризма как формы межкультурных интеракций.

Ключевые слова: этнокультурный туризм, этническая культура, экзистенциальная «захваченность», межкультурные интеракиии

(C) Дашкова Е.B., 2021 
Вестник ЮРГТУ (НПИ). Серия: Соииально-экономические науки. 2021 г. Т. 14. № 6 Bulletin of the SRSTU (NPI). Series: Socio-Economic Sciences. 2021. Vol. 14. № 6

Для цитирования: Дашкова Е.В. Практики этнокультурного туризма: экзистенциональные аспекты // Вестник Южно-Российского государственного технического университета. Серия: Сочиально-экономические науки. 2021. T. 14, № 6. С.228-236. http:// dx.doi.org/10.17213/2075-2067-2021-6-228-236.

Original article

\title{
ETHNOCULTURAL TOURISM PRACTICES: EXISTENTIONAL ASPECTS
}

\author{
Elena V. Dashkova

\begin{abstract}
Kadyrov Chechen State University, Grozny, Russia dashkova@mail.ru, ORCID: 12689863, AuthorID RSCI: 619408
\end{abstract}

\begin{abstract}
The purpose of the research is to determine the existential aspects of ethnographic tourism, the possibility of using the "capture» of a person by interest in ethnic cultures within the framework of ethnocultural tourism and the development of the ability to reconstruct one's own ethnic culture.
\end{abstract}

The methodological basis of the research is represented by the basic concepts of existentialism in the field of intercultural interaction. The scientific methods used include the method of causation, the method of comparison, the method of modeling.

Research results. The considered phenomenon of ethnocultural tourism is characterized by a high level of intercultural interactions occurring in the process of acquaintance with ethnic cultures. Intercultural interaction is an important part of social interactions that, as a rule, occur between carriers of different cultural patterns. intercultural interaction can have Differentiated forms associated with global cultural differences. But at the same time, the development of intercultural interactions between peoples, which makes it possible to overcome the crises of communication, contributes to the spread of human freedom, largely based on the responsibility of some communities to others. Ethnocultural tourism is a tool that allows you to strengthen contacts between peoples, aimed largely at crosscultural cooperation, overcoming xenophobia and other forms of intolerance. Based on the personalistic attitude in modern philosophy, as well as the attention that philosophers pay to communication and the language itself, we can conclude that a person is a person who is able to conduct an intercultural dialogue without being afraid or embarrassed, but at the same time respecting representatives of other cultures. partners and friends for intercultural interactions. The emergence of ethnocultural tourism testifies to progress in the field of human freedom. The analysis allows us to consider ethnocultural tourism as an independent spiritual value, important for the development of global culture.

The prospects of the research are in further research of ethnocultural tourism practices as a form of intercultural interactions.

Keywords: ethnocultural tourism, ethnic culture, existential «capture», intercultural interactions

For citation: Dashkova E. V. Ethnocultural tourism practices: existentional aspects // Bulletin of the South Russian State Technical University. Series: Socio-economic Sciences. 2021; 14(6): 228-236. (In Russ.). http://dx.doi.org/10.17213/2075-2067-2021-6-228-236. 
Введение. Рассматриваемый нами феномен этнокультурного туризма характеризуется высоким уровнем межкультурных взаимодействий, происходящих в процессе знакомства с этническими культурами, выходящими на свет из собственной потаенности. Межкультурное взаимодействие выступает важной частью социальных интеракций, происходящих, как правило, между носителями различных культурных паттернов. При этом ясно, что межкультурное взаимодействие может иметь дифференцированные формы, связанные с глобальными культурными различиями. В первую очередь понятно, что «традиционные» культуры могут быть детерминированы, например, мировыми религиями (христианство, ислам, буддизм) либо иметь отношение к древним шаманским или анимистическим представлениям и верованиям. Но вместе с тем развитие межкультурных интеракций между народами, позволяющее преодолевать кризисы коммуникации, способствует распространению человеческой свободы, во многом основанной на ответственности одних сообществ перед другими.

Методологические и теоретические основания исследования. Методологической основой данного исследования стал анализ философских и культурологических работ таких авторов, как М. Хайдеггер, М. Шелер, А. Томас, М. Д. Казаку, С. Яту.

Использовался системный подход, который ориентирует исследование на раскрытие целостности объекта, на выявление многообразных типов связей сложного объекта и сведение их в единую теоретическую картину. Инструментами для выявления специфики избранного объекта послужили сравнительно-исторический и сравнительно-сопоставительный методы, позволяющие выявить и сопоставить уровни в развитии изучаемого объекта, произошедшие изменения, провести исторические параллели.

Результаты. Рассматриваемый феномен этнокультурного туризма характеризуется высоким уровнем межкультурных взаимодействий, происходящих в процессе знакомства с этническими культурами. Межкультурное взаимодействие выступает важной частью социальных интеракций, происходящих, как правило, между носителями различных культурных паттернов. Межкультурное взаимодействие может иметь дифференцированные формы, связанные с глобальными культурными различиями. Но вместе с тем развитие межкультурных интеракций между народами, позволяющее преодолевать кризисы коммуникации, способствует распространению человеческой свободы, во многом основанной на ответственности одних сообществ перед другими. Этнокультурный туризм является инструментом, позволяющим усилить контакты между народами, направленные во многом на кросс-культурное сотрудничество, преодоление ксенофобии и других форм нетерпимости. Исходя из персоналистической установки в современной философии, а также того внимания, которое философы уделяют коммуникации и собственно языку, можно сделать вывод, что личностью является человек, способный вести межкультурный диалог, не боясь и не стесняясь, но вместе с тем уважая представителей других культур, партнеров и друзей по межкультурным интеракциям. Появление этнокультурного туризма свидетельствует о прогрессе в сфере человеческой свободы. Проведенный анализ позволяет рассматривать этнокультурный туризм в качестве самостоятельной духовной ценности, важной для развития глобальной культуры.

Обсуждение. Непосредственность восприятия в межкультурном взаимодействии способна обнажить базисные экзистенциалы, связанные с проявлением общих для всех людей эмоций. Таким образом, в контексте межкультурной коммуникации и репрезентации этнических культур может быть достигнут наиболее конкретный взгляд на корни человеческого бытия. Прежде всего, турист может быть поражен глубоким этическим содержанием раскрывающихся перед ним культурных традиций, а также их близости к природе и структурам сакрального. В этнических культурах других народов можно обнаружить обычаи, которые в собственной традиции в основном были утрачены, поэтому захваченность является важным экзистенциалом, предшествующим и выступающим основанием всей последующей человеческой деятельности. 
Очевидно, что захваченность предшествует пониманию, проникновению и интеллектуальному постижению интересующего предмета. В данной связи крупнейший российский философ XX века В.В. Бибихин предпочитал «говорить о человеке как о месте захваченности. Как о месте по-нятия, поятия, con-cepio, Be-griff, о человеке как понимании. Не будем совершать ошибку сознания, не станем воображать, будто есть некий источник спонтанного постижения, субъект, откуда исходят понятия как результат его мыслительной деятельности. Никакого понятия - con-cepio, Be-griff - никакой субъект никогда бы не схватил, если бы сам сначала сам не был захвачен» $[1$, с. 44]. Без захваченности смыслом общения люди не смогли бы понимать друг друга, было бы невозможно пробиться через ограду сложившихся культурных различий. Вместе с тем изначально незнакомая культура может так же захватить человека, как, впрочем, и стихия иностранного языка, которому индивид открывается в своей способности дальнейшего обучения.

Если человек согласно философской антропологии М. Шелера есть свободное существо, которое в отличие от других живых существ не сливается с миром, а открыто ему, это значит, что сам человек также может быть открыт навстречу любой культуре. Проблема человека как носителя «духовности» интересовала немецкого философа М. Шелера, который считал, что «основным определением “духовного” существа станет экзистенциальная независимость от органического, свобода, отрешенность от принуждения и давления, от “жизни” и всего, что относится к “жизни”, то есть в том числе его собственного, связанного с влечениями интеллекта. Такое "духовное" существо больше не привязано к влечениям и окружающему миру, но "свободно от окружающего мира" и, как мы будем это называть, “открыто миру"» [8, с. 53]. Поэтому человек может превращаться в незаинтересованного наблюдателя, который в своем созерцании руководствуется эстетическими категориями.

Реализовать свою «открытость» миру человек может посредством этнокультурного туризма. Впервые дефиниция «этнокультурный туризм» рассмотрена А.Г. Бутузовым, который определил его как «совокупность различных форм туристской активности, обусловленных стремлением к пониманию многообразия феноменов этнокультурной среды» [3, с. 82]. Этнокультурный туризм позволяет усилить контакты между народами, направленные во многом на кросс-культурное сотрудничество, преодоление ксенофобии и других форм нетерпимости. С.Н. Федорова, рассматривая этнокультурный туризм с культурологической точки зрения, отмечает: «Этнокультурный туризм способствует знакомству, выявлению, изучению и сопоставлению национальных характеров, ментальности, архетипов» [6, c. 133]. Не нужно опасаться того, что и опыт этнокультурного туризма окажется лишенным глубокого экзистенциального содержания. Напротив, лучший способ не только беглого знакомства, но и погружения в иные культурные миры открывается в период свободного досуга. Хотя с другой стороны нельзя исключать из нашей дескрипции тот факт, что с точки зрения принимающей стороны этнокультурный туризм в то же время остаётся предприятием коммерческим, рассчитанным на извлечение прибыли. К тому же этнокультурный туризм также может развиваться в тех регионах земного шара, где нет альтернативных экономических перспектив и драйверов развития. Но, тем не менее, рассматриваемый нами способ межкультурной интеракции остаётся одним из самых безопасных, потому что его основу составляют этические практики гостеприимства.

Для традиционных культур наиболее признанными ценностями выступают семья, многодетность, ритуалы, связанные с укреплением рода, особым почетом пользуются старшие, культивируется подчинение детей родительской воле. Именно поэтому традиционные ценности в связке с развитой этнокультурой находят отклик в среде людей модернизированного общества, желающих обрести почву под ногами и приобщиться к своим корням.

Вместе с тем этнические культуры, многие из которых реконструируются или возрождаются на наших глазах, в том числе и с целями развития этнического туризма, испытывают различное по своей реальной силе влияние со стороны религиозных традиций. Однако также очевидно, что чем сильнее религиозное влияние на культуру народа, тем 
легче ему сохранять свои традиции и, следовательно, такой этнос можно считать более консервативным, в том числе и в смысле организации повседневной жизни, почитания праздников и соблюдения наиболее важных традиций. Можно сказать, что чем более религиозным является народ, тем он более консервативен в плане реального обращения к традиционным ценностям, а также в организации семейной жизни и быта. Но при этом могут также возникать проблемы коммуникации и взаимодействия с представителями в большей степени модернизированных этнических групп. В данной связи правильно определить пропорции и возможности межкультурного взаимодействия на основе взаимного уважения обычаев и традиций. При этом не нужно забывать, что в условиях глобальных мегаполисов традиции и обычаи ещё недавних мигрантов могут подвергнуться существенным изменениям или корректировке, сохраняется также возможность их утраты уже в следующем поколении.

В современной ситуации межкультурного взаимодействия религия, особенно в её социальном измерении, становится одной из наиболее сложных и даже проблемных аспектов интеракции между представителями различных этнических групп. Так, например, М.Я. Яхьяев справедливо полагает, что «религия как духовная традиция крайне важна не только для человека верующего, но и для неверующего, который уважительно относится к своей цивилизационной идентичности, не отрывает себя от корней своей национальной культуры» [9, с. 82]. В современном мире вновь актуализированной стала проблема взаимодействия между традиционными носителями религии и людьми светскими, тем более атеистами или агностиками. Так межкультурное взаимодействие в подобных случаях намного усложняется, если к нему примешивается этнический фактор.

Здесь важно учитывать, что многие модернизированные народы являются преимущественно потребителями массовой культуры, причем «народная» культура у них ассоциируется с фольклором или даже с реконструкцией национализма. Известно, что в модернизированных обществах, особенно в западных, этнические культуры местных жителей зачастую пытаются возрождать на- ционалисты или в более широком смысле люди, придерживающиеся в целом правых политических взглядов. В данной связи можно отметить, что, например, на традиционные культуры народов Северного Кавказа активно воздействует религия ислама, тогда как традиционные культуры финно-угорских народов России в меньшей степени религиозны, но при этом получают определенные импульсы от сохранившихся языческих обрядов и верований.

Интересно, что в рамках этнокультурного туризма в наибольшей степени востребованными оказываются незападные культуры, причем наиболее аутентичными идентифицируются те из них, которые не так сильно отличаются от жизни и быта того этнического сообщества, чьи признанные представители главным образом задействованы в туристских практиках. Таким образом, уровень непосредственного взаимодействия с этнической культурой оказывается в описанной ситуации, максимально приближен к интеракциям, осуществляемым в повседневной, не связанной с туризмом сфере. Следовательно, и проникновение в подобную этническую культуру, знакомство или даже погружение в неё будет аутентичным за счёт связи между реальным бытом народа и репрезентацией его культурных богатств посредством туристских репрезентаций.

Многие этнические культуры обладают серьезными ресурсами социальной прочности и могут не только существовать, но и возрождаться, пока существует народ, считающий себя наследником данной культуры.

В целом межкультурное взаимодействие помогает гармонизировать отношение между этническими группами, то есть способствует лучшему пониманию, возникающему в процессе коммуникации между народами, причем подобное общение представляется безопасным, учитывая подготовку к нему сразу с двух сторон. Вместе с тем практики этнокультурного туризма позволяют реализовать свободу человека, а также право на захваченность другими культурами, которые способны вызвать в нем неподдельный интерес. В данной связи М. Хайдеггер отмечал, что реальность «встречи с сущим, отношение к сущему в любом способе его открытости возможно лишь там, где есть свобода. Сво- 
бода есть условие возможности открытости бытия сущего, условие возможности понимания бытия» [7, с. 361]. Поэтому очевидно, что в контексте этнокультурного туризма индивид оказывается в большей степени способным реализовать собственную свободу, тем более провести свои досуг с наибольшим интересом.

В основном захваченность осмысливалась в современной культуре сквозь призму экзистенциальной философии. С одной стороны, данный термин можно отождествить с понятием, которое противостоит свободе, поскольку нам может показаться, что в этом состоянии человек может быть скован, оказывается «взят в оборот», в захват надындивидуальных сил. Но более внимательный взгляд на захваченность показывает, что перед нами культурный феномен, напрямую связанный с эстетическим впечатлением. То есть речь идёт о свободном человеке, который захвачен какой-либо картиной, музыкой, выдающимся художественным произведением в довольно широком, но почти исключительно эстетическом смысле. Неудовлетворенность человека собой и собственным положением, а также скука заставляет его действовать, то есть размыкать окружающий его мир. «Человек, обладая свободой, есть открытый самотрансцендирующийся проект, самостоятельно ведущий свою жизнь и постоянно выходящий за пределы своего наличного “Я”. Неудовлетворенность собой выступает источником непрерывного стремления человека к самообновлению, что приводит к постоянной смене форм жизни и культуры как специфического способа самоосуществления человека» [5, с. 227-228]. При этом очевидно, что межкультурное взаимодействие будет понятным, если в его основе будет находиться язык искусства, поэтому перспективным может считаться появление практик этнокультурного туризма, базирующихся на погружении в народное искусство: музыку, пение и танцы народов мира.

Таким образом, открытость к другим культурным традициям становится ведущей линией интерпретации межкультурных интеракций, притом, что собственно встреча с определенным культурным содержанием должна ещё состояться. Наиболее безопасным образом встреча с другими культурными традициями может состояться в контексте ту- ристских практик, помогающих преодолеть возможные ксенофобские тенденции. При этом межкультурные интеракции предполагают большую ответственность как принимающей стороны, так и самих туристов в репрезентации культуры. Перед нами здесь представлено двустороннее взаимодействие, которое при благоприятном исходе должно не просто удовлетворить, но и обогатить обе стороны, вступающие в него. Входящий в общение турист должен получить позитивное впечатление о традициях и обычаях того народа, который вызвали в нем неподдельный интерес. Но, следовательно, «расхожий» и привычно ожидаемый комфорт (как впрочем, и обычные для туристов требования к сервису) не является ведущим аспектом этнокультурного туризма. Возможен и риск разочарования, связанный с неожиданностью предложенных феноменов. Ведь вполне ясно, что традиции изначально не были созданы для «обычного» (наиболее коммерциализированного и стандартного) туристского формата, когда знакомство с ними происходит либо в «лубочном» формате восприятия, либо в беглом отвлеченно-поверхностном ознакомлении. Аутентичность этнокультурных практик может даже показаться «грубостью» и даже «дикостью» туристу, который не был должным образом подготовлен. Поэтому, рассматривая требования подготовки как туристов, так и в не меньшей степени принимающей их стороны, можно предположить, что вокруг подобных практик могут вполне складываться самобытные субкультуры.

Отличительной чертой межкультурных интеракций выступает определенная сложность, как правило, связанная с возможной непривычностью подобного взаимодействия. С одной стороны, этнокультурный туризм открывает новые возможности восприятия других обычаев и традиций в их наглядности, но при этом требует более внимательного ознакомления с культурными практиками. Поэтому к подобному «экзистенциальному» туристу ситуация взаимодействия предъявляет определенные требования дисциплины и готовности самостоятельного обучения. Участвующий в практиках межкультурного взаимодействия турист должен быть изначально позитивно настроен к участию в подобных мероприятиях, а также к возможным 
трудностям коммуникативного процесса. Вместе с тем специфика этнокультурного туризма заключается в том, что предложенные здесь человеку практики позволяют реализовать свободное выражение представленной, сохраняемой или реконструируемой культурной традиции.

Опыт межкультурных интеракций в современном мире становится настолько необходимым, что нужны специальные государственные программы по развитию этнокультурного туризма. Поэтому для многих людей оказывается необходимым усваивать навыки межкультурного взаимодействия, особенно в полиэтнических регионах и крупных городах, которые являются реципиентами массовой миграции, в том числе из иностранных государств. Так, например, установленные и интериоризированные стандарты культуры в целом активно действуют на поведение людей «как имплицитные теории, усвоенные в процессе социализации» $[11$, с. 153]. В условиях глобализации межкультурные интеракции в значительной степени теряют свой факультативный статус для многих жителей Земли и отчасти переходят в разряд необходимых, если не обязательных практик, позволяющих в лучшей степени наладить возможные контакты с культурным окружением.

Заключение. Этнокультурный туризм развивается динамично, и, структурируя этот вид туристской деятельности, можно выделить такие разновидности этнокультурного туризма (по Бутузову), как этнографический, антропологический, этнический и ностальгический туризм [2].

В целом этнокультурный туризм, за исключением его наиболее экстремальных форм (как, например, путешествие к диким племенам), не может избежать обвинений в подделках аутентичного опыта встречи с инаковостью. Вместе с тем не стоит сильно фетишизировать опыт аутентичности, полагая, что есть ритуалы, традиции и обычаи, которые оставались неизменными на протяжении целых тысячелетий. В действительности даже самые консервативные традиции претерпевали, на первый взгляд, незаметные изменения, связанные с адаптацией к изменяющимся условиям существо- вания, кроме этого, в процесс культурного воспроизводства просачивались определенные инновации, носящие «эндогенный» характер [10], поэтому для этнокультурного туризма характерна «карнавальность», которая предполагает включенность туристов в игру. Анимационные программы стали неотъемлемой частью этнокультурного туризма. Таким образом, между этнокультурами, национальными культурами и массовой культурой происходит непрекращающийся обмен, правда, проходящий через селективные фильтры, которые позволяют обозначить и сохранить между ними границу.

Современный исследователь Ван Тин отмечает, что туризм в современном мире «является нематериальной услугой, создающей возможности для реализации потребностей членов общества. В основе понимания данного явления общественной жизни положена организация досуга в рамках межкультурного взаимодействия: для культурного общения, познания истории и традиций разных народов и укрепления дружбы» [4, с. 77]. Следовательно, здесь мы обнаруживаем редкую возможность общения между представителями различных этнокультур в определенных условиях, которые могут значительно отличаться от «лабораторных». Таким образом, оказывается, что само межкультурное взаимодействие накладывает на туристскую отрасль вполне определенную ответственность, оно сопряжено с пониманием разнообразия в сфере этических вопросов, а главное - туристским компаниям приходится рекрутировать в свои ряды людей, имеющих непосредственное отношение одновременно как к современной науке, так и этнической культуре.

\section{Список источников}

1. Бибихин В. В. Собственность. Философия своего. СПб.: Наука, 2012. 536 с.

2. Бутузов А.Г. Состояние и перспективы развития этнокультурного туризма в Российской Федерации // Сервис в России и за рубежом. 2009. №4. С. 11-13.

3. Бутузов А.Г. Этнокультурный туризм в Московской области: состояние и перспективы развития // Сервис в России и за рубежом. 2010. №4. С. 3-14. 
Вестник ЮРГТУ (НПИ). Серия: Сочиально-экономические науки. 2021 г. T. 14. № 6 Bulletin of the SRSTU (NPI). Series: Socio-Economic Sciences. 2021. Vol. 14. № 6

4. Ван Тин. Туризм как способ межкультурного взаимодействия в условиях глобализации // In Situ. 2016. №6. С. 75-79.

5. Волохова Е.В. Философия свободы человека в современной культуре. Новочеркасск: ООО «Лик», 2019. 272 с.

6. Федорова С.Н.Этнокультурныйтуризм как культурологический феномен: сущность и структура // Вестник Северо-Восточного федерального университета им. М.К. Аммосова. 2014. Т. 11. №4. С. 129-135.

7. Хайдеггер М. О существе человеческой свободы. Введение в философию. СПб.: Изд-во «Владимир Даль», 2018. 416 с.

8. Шелер М. Положение человека в Космосе // Проблемы человека в западной философии: Переводы. М.: Прогресс, 1988. 552 с.

9. Яхьяев М.Я. Светское и религиозное в современном мире // Исламоведение. 2011. №2. C. 90-95.

10. Cazacu M.D., Iatu C. Ethnographic tourism - promoter of the identity of area. Lucrariie SeminaruluiGeografic Dimitrie Cantemir. 2015. №39. P. 139-152.

11. Thomas A. Grundriss der Sozialpsychologie. Band 2. Individuum - Gruppe - Gesellschaft. G: Hogrefe, 1992.

\section{References}

1. Bibihin V.V. Sobstvennost'. Filosofija svoego [Property. The philosophy of your man]. Saint Petersburg: Nauka, 2012. 536 p. (In Russ.).

2. Butuzov A.G. Sostojanie i perspektivy razvitija jetnokul'turnogo turizma v Rossijskoj Federacii [The state and prospects of development of ethno-cultural tourism in the Russian Federation]. Servis v Rossii i za rubezhom [Service in Russia and abroad]. 2009; (4): 11-13. (In Russ.).

3. Butuzov A.G. Jetnokul'turnyj turizm v Moskovskoj oblasti: sostojanie i perspektivy razvitija [Ethnocultural tourism in the Moscow region: state and prospects of development]. Servis v Rossii i za rubezhom [Service in Russia and abroad]. 2010; (4): 3-14. (In Russ.).

4. Van Tin. Turizm kak sposob mezhkul'turnogo vzaimodejstvija v uslovijah globalizacii [Tourism as a way of intercultural interaction in the context of globalization]. In Situ. 2016; (6): 75-79. (In Russ.).

5. Volohova E.V. Filosofija svobody cheloveka v sovremennoj kul'ture [Philosophy of human freedom in modern culture]. Novocherkassk: OOO «Lik», 2019. 272 p. (In Russ.).

6. Fedorova S. N. Jetnokul'turnyj turizm kak kul'turologicheskij fenomen: sushhnost' i struktura [Ethnocultural tourism as a culturological phenomenon: essence and structure]. Vestnik Severo-Vostochnogo federal'nogo universiteta im. M. K. Ammosova [Bulletin of the North-Eastern Federal University named after M.K. Ammosov]. 2014; 11(4): 129-135. (In Russ.).

7. Hajdegger M. O sushhestve chelovecheskoj svobody. Vvedenie v filosofiju [About the essence of human freedom. Introduction to philosophy]. Saint Petersburg: Izd-vo «Vladimir Dal'», 2018. 416 p. (In Russ.).

8. Sheler M. Polozhenie cheloveka v Kosmose [The position of man in Space]. Problemy cheloveka v zapadnoj filosofii: Perevody [Human problems in Western philosophy: Translations]. Moscow: Progress, 1988. 552 p. (In Russ.).

9. Jah'jaev M. Ja. Svetskoe i religioznoe v sovremennom mire [Secular and religious in the modern world]. Islamovedenie [Islamic Studies]. 2011; (2): 90-95. (In Russ.).

10. Cazacu M.D., Iatu C. Ethnographic tourism - promoter of the identity of area. Lucrariie SeminaruluiGeografic Dimitrie Cantemir. 2015. №39. P. 139-152.

11. Thomas A. Grundriss der Sozialpsychologie. Band 2. Individuum - Gruppe - Gesellschaft. G: Hogrefe, 1992.

Статья поступила в редакиию 28.11.2021; одобрена после рецеензирования 05.12.2021; принята к публикаиии 18.12.2021.

The article was submitted on 28.11.2021; approved after reviewing on 05.12.2021; accepted for publication on 18.12.2021. 


\section{ИНФОРМАЦИЯ ОБ АВТОРАХ}

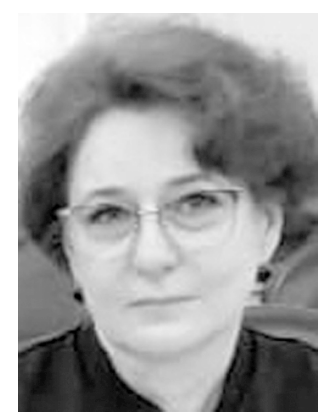

Дашкова Елена Валерьевна - кандидат философских наук, декан факультета географии и геоэкологии, и.о. заведующего кафедрой «Туризм и индустрия гостеприимства», Чеченский государственный университет им. А. А. Кадырова.

Россия, г. Грозный, ул. А Шерипова, 32

Elena V. Dashkova - Candidate of Philosophical Sciences, Dean of the Faculty of Geography and Geoecology, Acting Head of the Department of Tourism and Hospitality Industry, Kadyrov Chechen State University.

32 A. Sheripova st., Grozny, Russia 